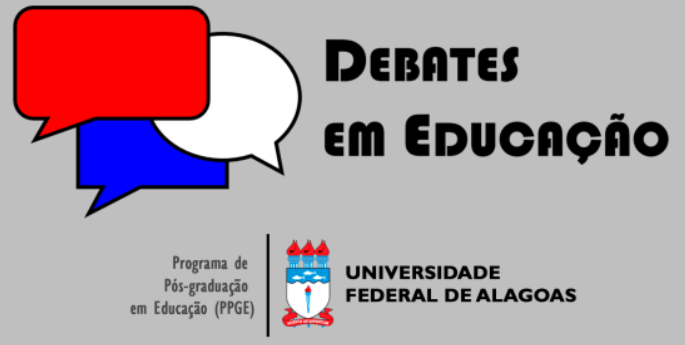

ISSN Eletrônico 2175-6600

Vol. I | | No. 23 | Jan./Abr. | 2019

Itacir Marques Luz

(9) iD

Universidade de Integração da Lusofonia Afrobrasileira

(UNILAB)

itacirluz@gmail.com

\section{NO INTERIOR DA MEMÓRIA: CAMINHOS, SÍMBOLOS E FONTES DE UM PASSADO AFROBRASILEIRO}

\section{RESUMO}

Este artigo se propõe a discutir as representações sobre o papel da população negra, particularmente no contexto do Ceará, tendo em vista a perspectiva historicamente difundida sobre a pouca presença desta população no âmbito local e sua repercussão, portanto, na produção da imagem do povo cearense a partir dos diferentes espaços de memória. Diante disso, coloca-se o desafio de rediscutir tanto as bases históricas de tal representação, quanto os meios pelos quais vem sendo difundida sistematicamente no imaginário geral. Para tanto, tomamos por base no mapeamento que vem sendo desenvolvido sobre os "vestígios" da população negra (lugares, documentos, artefatos, práticas artístico-culturais) de sua trajetória na região do Maciço do Baturité, de modo a se discutir tais "lugares de memória".

Palavras-chave: Memória. Africanidades. História local.

\section{INSIDE THE MEMORY: PATHWAYS, SYMBOLS AND SOURCES OF AN AFROBRAZILIAN PAST} \begin{abstract}
This article discusses representations about the role of the black population, particularly in the context of Ceará, considering the historically widespread perspective on the low presence of this population in the local scope and its repercussion, therefore, in the production of the image of the people of Ceará from the different memory spaces. The challenge is to rediscuss both the historical bases of such representation and the means by which it has been systematically diffused in the general imaginary. In order to do so, we take as a basis the mapping that has been developed on the "vestiges" of the black population (places, documents, artifacts, artistic-cultural practices) of their trajectory in the Baturité Massif region, in order to discuss such "places from memory".
\end{abstract}

Keywords: Memory. Africanities. Local History.

Submetido em: 06/10/2018

Aceito em: 04/04/2019

Ahead of print em: I 1/04/2019

Publicado em: 25/04/2019

d. http://dx.doi.org// 0.28998/2175-6600.2019v1 In23p572-582 


\section{INTRODUÇÃO}

Os avanços político-institucionais no âmbito curricular nos anos mais recentes do Brasil, com ênfase no que se refere à prescrição do ensino de História e Cultura Afrobrasileira e à História e Cultura Indígena na Educação Básica ${ }^{1}$, embora representem um enfrentamento significativo às tradicionais abordagens que exotizam e coisificam esses segmentos culturais ou cosmovisões, devendo, por isso, serem destacados, infelizmente ainda não foram capazes de eliminar as dificuldades ainda existentes no panorama geral dos programas de ensino e nas práticas de sala de aula do país no que tange ao tema das identidades e pertencimentos étnico-raciais.

Isso porque a escola continua sendo um lugar importante para desconstrução de ideias que reduzem a população negra a uma condição humana inferior, representação essa forjada para interferir e controlar o povo brasileiro numa de suas maiores características: a identidade plural. Portanto, tomar consciência de que o ambiente escolar favoreceu e ainda favorece a construção de uma anti-imagem e de sentimentos negativos impostos pelo racismo é o primeiro passo à construção de uma prática pedagógica realmente inclusiva na medida em que em toma como princípio do respeito à diversidade.

Nesse sentido, o artigo aqui proposto traz algumas reflexões no que se refere à memória, história e patrimônio afrobrasileiros, partindo das questões mobilizadas no reconhecimento do conjunto desses saberes e expressões tão desconsideradas epistemológica e pedagogicamente ao longo da trajetória desse país e que, por isso, ainda tendem a ser tratados não enquanto conhecimentos e saberes no seu sentido mais profundo e complexo, e sim enquanto costumes relacionados à categoria meramente do exótico ou folclórico.

Para isso, tomaremos por base empírica a experiência vivida no contato com comunidades quilombolas e comunidades negras rurais, nas quais foram desenvolvidas ações por meio do projeto de extensão intitulado "Negras Memórias: (re) conhecendo os lugares, símbolos e expressões da história afrobrasileira" ${ }^{2}$, o qual tem como ponto de partida a necessidade de problematizar a invisibilização da presença negra no território cearense, a partir da valorização dos seus diferentes rastros e legados. Significa, portanto, um esforço pedagógico e sociológico de realçar positivamente a experiência da população negra na história do Brasil considerando a particularidade da visão desses sujeitos com suas referências legadas pelo "mundo africano" e da síntese disso com as outras referências civilizatórias encontradas no Novo

\footnotetext{
' Em janeiro de 2003 foi promulgada a Lei 10.639, que, alterando o texto da LDB 9394/96, tornou obrigatório o ensino da história africana nas escolas brasileiras (os PCNs apenas sugeriam os conteúdos). A essa lei seguiu-se, já em 2004, a formulação das Diretrizes Curriculares Nacionais para a Educação das Relações Étnico-Raciais e para o Ensino de História e Cultura AfroBrasileira e Africana. OLIVA, Anderson Ribeiro. A história africana nas escolas brasileiras. Entre o prescrito e o vivido, da legislação educacional aos olhares dos especialistas ( 1995-2006). HISTÓRIA, São Paulo, 28 (2): 2009

2 Projeto de extensão vinculado ao Programa Institucional de Bolsas de Extensão, Arte e Cultura - PIBEAC, edição 20 I 8.
} 
Mundo, demonstrando o quanto conseguiram não apenas sobreviver ao jugo de um sistema escravista no passado, mas também mover-se de modo propositivo frente à realidade adversa, criando mecanismos socioculturais de atuação.

\section{AFRONTANDO O MITO DA INEXISTÊNCIA}

O discurso da primazia na concessão da liberdade dos escravizados no estado do Ceará trouxe consigo algumas implicações ao imaginário local, algo que parece ainda presente apesar dos estudos e debates já existentes sobre esse tema, tanto no âmbito mais geral, abordando o escravismo como um sistema socioeconômico que vigorou no Brasil como um todo, quanto no âmbito específico do que é atualmente o território cearense ${ }^{3}$. Essa espécie de "aura" humanitária presente em tal discurso desconsidera a complexidade política que envolveu esse processo, com todas as suas contradições e os diferentes jogos de interesse por parte de determinados grupos sociais na produção dessa imagem idílica do que foi a escravidão e do apregoado papel redentor das elites locais e nacionais.

Vale lembrar que este mesmo lugar onde se afirma o pioneirismo da abolição da escravatura foi um dos poucos a conceder indenização aos proprietários de escravos pela perda dessa "mercadoria", uma vez que as duas maneiras mais comuns de se obter capital através dos escravizados naquele momento eram as alforrias via Fundo de Emancipação e o tráfico interprovincial. Isso irá fomentar na memória coletiva do século XIX a ideia de que os escravizados valiam mais vendidos do que em convivência social, abrindo, assim, uma outra perspectiva sobre esse pioneirismo ou "redencionismo" cearense.

No curso do século $X X$, se notabilizará o discurso de que o Ceará foi - e alguns insistem em acredita que ainda seja - um Estado quase sem negros, e cuja explicação tradicionalmente apresentada pela historiografia seria por ter sido uma província sem um sistema escravocrata sólido, enfatizando basicamente a área econômica em função dos chamados ciclos produtivos e as formas de trabalho em cada um desses momentos. Neste caso, isso coloca-se na base do argumento sobre o suposto pioneirismo do Ceará em relação ao fim da escravidão e da primazia sobre a abolição, mas também que, como destaca Funes (2000), tem servido para fortalecer mais ainda a invisibilização da população negra com toda sua atividade cultural difundida nas diversas regiões do estado e por diversas expressões, ajudando a fortalecer o discurso do branqueamento no contexto local na medida em que impõe à presença dos africanos e seus descendentes um caráter ocasional.

\footnotetext{
${ }^{3}$ Sobre isso, ver: FUNES, Eurípedes Antônio. Negros no Ceará. In: SOUZA, Simone(coord.). Uma Nova História do Ceará, Fortaleza: Demóclito Rocha, 2000.; SILVA, Eduardo. O negro e a conquista da abolição. In: FONSECA, Denise P. R. (org.) Resistência e Inclusão. V. I . Rio de Janeiro: PucRio, 2003; SOBRINHO, José Hilário Ferreira. Catirina, minha nêga, tão querendo te vendê: Escravidão, tráfico e negócios no Ceará do século XIX (|850- |88 I). Fortaleza: SECULT/CE, 20 I I.
} 
Por seu lado, o segmento historiográfico da História Cultural assinala a reinvenção do passado através das práticas e representações de mundo partilhadas pelos sujeitos históricos, e tal noção sobre práticas e representações nos ajuda no debate sobre os vestígios e legados da presença negra no Ceará, considerando a necessidade mesmo de enxergar os sinais mais sutis da presença desses sujeitos no curso da história local, pelo próprio lugar social subalternizado e, por conseguinte, invisível para os registros históricos oficiais, além de terem sido notabilizados como um detalhe, quase inexistentes. De acordo com D'Assunção (201 | p. |2):

"representação", no campo da História e das Ciências Humanas, é uma palavra com múltiplos significados. As "práticas" se referem aos fazeres, aos modos de agir, as "representações" dizem respeito aos modos de ver e conceber o mundo através de imagens, de esquemas mentais. Assim, há um entrelaçamento entre o fazer e o conceber, ou seja, há uma arquitetura entre "práticas" e "representações".

Essa perspectiva sobre os objetos e os temas de abordagem têm se expandido de forma significativa, viabilizando uma variedade de estudos sobre a cultura popular, a cultura letrada e as representações sociais, dentre outros. Na contemporaneidade, portanto, compreende-se que todos os seres humanos produzem cultura uma vez que se comunicam por meio dos gestos, do corpo, do seu modo de vida. Constituem, nas palavras do citado autor:

[...] práticas culturais não apenas a feitura de um livro, uma técnica artística ou uma modalidade de ensino, mas também os modos como, em uma dada sociedade, os homens falam e se calam, comem e bebem, sentam-se e andam, conversam ou discutem, solidarizam-se, morrem ou adoecem, tratam seus loucos ou recebem os estrangeiros (D'ASSUNÇÃO, 20 I I, p. 17).

No que tange ao trabalho com essas comunidades negras, a articulação entre estas expressões da prática cotidiana com os registros históricos ditos oficiais ajudam na percepção das vozes silenciadas da História do Ceará, neste caso em particular, da população negra. No centro do cruzamento entre a linha da História e a do passado, a memória nos mostra o que deve ser lembrando, mas também nos omite aquilo que escolheu-se esquecer, uma vez que se trata de um "utensílio mental" feito pelos sujeitos históricos ao longo dos séculos e, por isso, ela, a memória, é tão seletiva, quanto a História e as duas têm o passado como seu principal sujeito histórico.

Tal mudança de perspectiva também implica numa ampliação do campo do próprio documento histórico. Nesse sentido, de acordo com Le Goff (1988), é a Nova História que surge como a principal responsável por substituir a história fundada essencialmente nos textos, no documento escrito, por uma "revolução documental" baseada numa multiplicidade de documentos: escritos de todos os tipos, documentos figurados, produtos de escavações arqueológicas, documentos orais, etc. No entanto, essa verdade vivida pela história hoje não deixa de ter suas ambiguidades e por isso deve ser acompanhada de muita criticidade, uma vez que, como destaca o autor: 
O documento não é inocente, não decorre apenas da escolha do historiador, ele próprio parcialmente determinado por sua época e seu meio; o documento é produzido consciente ou inconscientemente pelas sociedades do passado, tanto para impor uma imagem desse passado, quanto para dizer "a verdade" (LE GOFF, 1988 p.54).

Junto a isso coloca-se a crítica do documento como monumento, uma vez que, como alerta o mesmo Le Goff (1996) que o documento não é qualquer coisa que fica por conta do passado e sim, um produto da sociedade que o fabricou segundo as relações de forças que aí detinham o poder. Por isso, só a análise do documento como monumento permite à memória coletiva recuperá-lo e ao historiador usálo cientificamente, isto é, com pleno conhecimento de causa.

No bojo dessa crítica à interpretação histórica, Moore (2007) chama atenção à ideia de que os povos negros teriam desempenhado um papel irrisório na longa trama da humanidade, algo que, salienta o autor, foi forjado durante o recente período da conquista das Américas e a escravização dos africanos nestas terras. Por esse prisma os negros teriam sido, no máximo, meros coadjuvantes na História, até mesmo no seu próprio continente de origem.

Essa perspectiva eurocêntrica da história do mundo passa a ser questionada a partir dos movimentos de descolonização dos países africanos e também das Américas, emergindo daí diferentes sujeitos sociais e com eles, a possibilidade de reatar os laços com tradições culturais marginalizadas, a exemplo da experiência histórica dos povos africanos e seus descendentes e da importância do papel deste continente no quadro mais amplo da história da humanidade.

A demanda por tal mudança de mentalidade e tal processo de reconhecimento traz também um desafio para o campo educacional, tendo em vista que este é cada vez mais provocado a rever as perspectivas e as abordagens adotadas até então sobre a questão da diversidade cultural e étnico-racial. Segundo Moreira e Candau (2005), no entanto, apesar das dificuldades e dúvidas ainda existentes por parte de muitos docentes, significativas experiências têm sido desenvolvidas, tanto no âmbito das escolas como de outros espaços de educação não formal, de modo a transcender o que chamam de "pluralismo benigno" de visões correntes de multiculturalismo e a afirmar as vozes e os pontos de vista de minorias étnicas e raciais marginalizadas e de homens e mulheres das camadas populares.

Para Hall (1997), por exemplo, a cultura é elemento central no cenário contemporâneo justamente por seu papel constitutivo em todos os aspectos da vida social. Para o autor, estamos mesmo diante de uma revolução cultural, evidenciada pela significativa expansão do domínio configurado por instituições e práticas culturais. Além disso, os meios de produção, circulação e troca cultural também se ampliam, graças ao desenvolvimento da tecnologia, particularmente da informática. Porém, essas transformações culturais desenvolvem-se também de forma bastante aguda no nível do microcosmo e a expressão "centralidade da cultura", refere-se exatamente à forma como a cultura penetra em cada recanto da vida social contemporânea, tornando-se fundamental no modo como o cotidiano é configurado e 
modificado. Portanto, a cultura não pode ser ignorada ou estudada como variável sem importância, secundária ou dependente em relação ao que faz o mundo se mover. Ao contrário, deve ser vista como algo fundamental, constitutivo, que determina a forma, o caráter e a vida interior desse movimento.

Mas além desse tipo de centralidade da cultura, Hall ( 1997) também realça o lugar central ocupado pela cultura no processo de formação de identidades sociais, tendo em vista que toda prática social depende do significado e com ele tem relação. E a cultura é uma das condições constitutivas de existência dessa prática, o que faz com que toda prática social tenha uma dimensão cultural.

É a relação entre as culturas que, portanto, caracteriza o universo escolar. Uma relação esta atravessada por tensões e conflitos, os quais tendem a se acentuar quando as culturas crítica, acadêmica, social e institucional, profundamente articuladas, tornam-se hegemônicas e tendem a ser encaradas como absolutas em detrimento da cultura experiencial com suas profundas raízes socioculturais. Segundo Hall (1997, p. 45):

Em vez de preservar uma tradição monocultural, a escola está sendo chamada a lidar com a pluralidade de culturas, reconhecer os diferentes sujeitos socioculturais presentes em seu contexto, abrir espaços para a manifestação e valorização das diferenças. É essa, a nosso ver, a questão hoje posta. A escola sempre teve dificuldade em lidar com a pluralidade e a diferença. Tende a silenciá-las e neutralizá-las. Sente-se mais confortável com a homogeneização e a padronização. No entanto, abrir espaços para a diversidade, a diferença, e para o cruzamento de culturas constitui o grande desafio que está chamada a enfrentar.

Silvério (2005) destaca que pensar o futuro nos obriga a rever o passado de forma crítica sem o que não será possível entender porque os subalternos procuram alterar suas condições de acesso em diferentes dimensões da vida social. No caso dos negros e do movimento social negro, o autor entende que o retorno do debate sobre raça tem sido estratégico para desvendar os caminhos da construção social da diferença que se transformou em desigualdade.

A compreensão crítica do passado é fundamental para entender o presente e construir um futuro em que a raça/etnia efetivamente não seja um operador permanente de desigualdades de oportunidades. Por sua vez, a complexidade com que essa problemática precisa vir a ser trabalhada tem como base uma dimensão multidimensional.

\section{MEMÓRIA E AFIRMAÇÃO NEGRA NO INTERIOR}

As repercussões deste processo de crítica e mudança também tende cada vez mais a se expressar na compreensão da importância do conhecimento histórico junto aos sistemas educacionais, de modo a transformar a representação sobre o papel da África e dos descendentes de africanos na história do mundo. Uma das expressões disso foi a criação da Lei 10.645/03, que a altera a Lei de Diretrizes e Bases da 
Educação Nacional e estabelece a obrigatoriedade do ensino de História e Cultura AfroBrasileira e Africana nas escolas do Ensino Fundamental e Médio.

Na direção dessa história que possa explicitar as vinculações entre diferentes aspectos de uma realidade sociocultural, tal entrelaçamento possibilita um exercício epistemológico, principalmente se o historiador define como objeto de sua investigação práticas e expressões dentro do campo sócio-políticocultural, colocando-as num papel de destaque e não meramente como decorrência da vida econômica. Nessa tarefa de construção de uma outra perspectiva sobre a história dos africanos e afrodescendentes, os processos educativos assumem um caráter fundamental, tendo em vista que é:

(...) uma prática social e histórica que produz representações ideologias, imagens e valores os quais precisam ser investigados; por isso precisamos explicitar caminhos epistemológicos que deem conta do estudo dessas categorias no sentido de compreender mais profundamente as práticas e os processos educacionais (MARTINS, 2006 pp. I I0- I I I).

Partindo dessa compreensão, a abordagem dos eventos e processos históricos da região do Maciço do Baturité precisa considerar a dimensão identitária da população local, o que envolve a observação de elementos diversos, muitas vezes ignorados pela historiografia tradicional por suas características ditas sutis. Ao discutir essa relação entre o ensino da história e a construção da identidade, Zamboni (1993), destaca os múltiplos significados da noção de lugar em meio a esse debate. Lugar, nesse sentido, é a segurança, casa, o bairro, a cidade, e a todos esses espaços as pessoas estão ligadas física e emocionalmente, adquirindo pertencimento e concretizando suas identidades. Para a autora, portanto, o estudo do lugar tem um papel essencial no ensino da História por ser um espaço onde ocorre naturalmente a interrelação entre os elementos físicos, biológicos e humanos, e também por ser ponto de partida para a aquisição de novos conhecimentos:

O lugar, a casa, a rua ou a cidade são o universo da criança. Pela sua natureza., contém em si os elementos que o caracterizam. A casa, por exemplo, é um espaço físico, um lugar que abriga um número de pessoas ligadas entre si por um determinado elo de amizade, parentesco, de afetividade. São pessoas que dispõem e organizam este espaço e as relações sociais, segundo critérios culturais próprios, que os individualizam e os identificam (ZAMBONI, 1993, p. 9).

Ainda segundo a autora, a identificação da maneira de viver, dos costumes presentes no cotidiano de um grupo determinado de pessoas é o primeiro passo para o estudo do lugar e da sua identidade. Para os sujeitos, os objetos do estudo serão concretos e determinados, algo apenas possível de contemplar pela perspectiva da história da pessoa comum, do povo. Na construção da história do lugar, na identificação da sua identidade, o ensino da História centra-se no sujeito concreto e não as instituições ou no modo de produção. Desta forma, o campo de investigação do professor se amplia e o suscita a dialogar com outros campos do conhecimento, como a literatura, a música, a demografia, a antropologia, dentre outros, desconstruindo a ideia da história do lugar em si mesmo. 
Nessa perspectiva, justifica-se o desafio de fomentar espaços e ações que promovam e valorizem a região do Maciço do Baturité, tanto por sua potencialidade de expressar a história das pessoas, dos comuns, mas também pela necessidade de visibilizar a presença e as contribuições da negra nesse contexto.

O trabalho de catalogação e divulgação dos lugares, símbolos e expressões da presença africana na região do Maciço do Baturité não apenas se coloca como um meio de fomentar a produção de um conhecimento sobre a História local, indagando sobre a formação étnico-racial das populações dessa região, com seu conjunto de práticas culturais e econômicas, considerando os a influência desta presença africana nesse processo de formação microrregional, mas também representa mais passo no reconhecimento desta presença negra na história do Ceará como um todo. Além disso, a participação direta das novas gerações de moradores das localidades acessadas vem sendo possível fundamental para ajudar a visibilizar e ampliar o conhecimento sobre o tema, fortalecendo também a integração da comunidade acadêmica com a população local.

Nesse sentido, o projeto Negras Memórias afirma sua meta de fomentar o interesse da população em geral pela História Local a partir do contato e da compreensão sobre as influências africanas no Ceará. Para isso, reconhecemos que um dos meios fundamentais de difusão desse processo é, sem dúvida, o espaço escolar, no qual os estudantes do Ensino Básico podem travar contato com tal reflexão a partir do trabalho com os instrumentos metodológicos da História (fontes, fato, tempo, memória). Vale lembrar que tratar de história da África no Brasil é contribuir para o cumprimento da Lei 10.639/03, valorizando as culturas africanas base da formação identitária brasileira. Por isso, coloca-se a relevância do contato dos jovens do Ensino Básico com a História da sua própria cidade ou comunidade, focalizando possíveis influências culturais africanas, na medida em que propõe-se olhar para a História do negro no Ceará contemplando a dimensão cultural nas suas diversas manifestações, como expressão dessa presença (artefatos, práticas populares, mitos, cotidiano do município - cidade/campo).

Entendemos que tal alcance junto a esse público se torna possível não apenas pelas características e perspectiva metodológica do projeto em si, mas também por este estar vinculado à própria Unilab, com todo o trabalho singular que esta instituição pública de ensino, pesquisa e extensão vem realizando na região, dentre os quais, o aprofundamento do contato com as culturas africanas que muitas vezes é vista como algo de fora, mantendo a negação da negritude cearense. E como expressão dessa perspectiva da instituição, o projeto de extensão Negras Memórias entende que o estudo da bagagem cultural existente no Estado pode aproximar visões de mundo que são simplesmente definidas como diferentes, mas são práticas de muitas intersecções. A aproximação do conhecimento sobre afrodescendentes cearenses pode trazer uma maior integração da comunidade acadêmica com a população local. O contato entre a academia e o sistema de Ensino Básico nesse contexto possibilitará a circulação de informações entre extratos sociais 
separados por campos simbólicos diferentes, trazendo a troca vários conteúdos afins, mas principalmente, nesse caso, a presença africana no Ceará.

\section{PROMOVENDO REENCONTROS IDENTITÁRIOS}

Para o desenvolvimento deste projeto contamos com a articulação entre a equipe de integrantes da universidade e os sujeitos dos diferentes espaços sociais (escolas, associações, agremiações, órgãos públicos, etc.), de forma que sejam valorizados os diversos depoimentos coletados e as experiências registradas (idosas/idosos, lideranças comunitárias, brincantes, religiosos, artistas, etc.), entendendo-os não apenas como testemunhas do processo histórico, mas também como resultado desse mesmo processo. Paralelamente, também recorremos aos registros escritos disponíveis nos acervos locais, além da observação das manifestações culturais existentes nas comunidades desses municípios, seja na sua expressão artística, (danças, músicas, religiosidades, etc.); seja na forma de práticas e papeis sociais de referência no cotidiano.

Como já enunciado, a abordagem empregada no trabalho toma, obviamente, uma dimensão sócio-cultural, marcada pelos rastros da memória e seu alcance no tempo cronológico como cenário que o testemunho se refere e qual a relação deste testemunho com a realidade social, lugar social que ocupam os personagens das histórias relatadas. Mas também constitui a abordagem uma dimensão político-social, marcada pelos registros escritos, na forma de documentos oficiais sobre eventos, leis, demarcações, bens, cerimoniais, dados contábeis, etc., a qual se somará a dimensão da cultura patrimonial, entendida aqui pelos rastros da longa duração, através de símbolos das práticas culturais em monumentos, artefatos arqueológicos e nomenclaturas.

Portanto, cabe à equipe do projeto identificar e registrar as fontes históricas, sejam elas depoimentos orais ou registros impressos (jornais, leis, manuscritos, etc.), além da observação de monumentos, artefatos e imagens, num diálogo permanente com uma bibliografia pertinente ao tema. Isso significa entender as especificidades de cada fonte, passando pelo conceito do que é História, fato, memória, bem como a presença e atuação da população negra no Ceará e no Brasil como um todo, para além da leitura hegemônica de subalternidade relacionada ao escravismo desses sujeitos.

Periodicamente são realizados encontros formativos que permitem entrecruzar e analisar as informações registradas. Como já enunciado, juntamente os suportes documentais, a História Oral vem servindo como uma fonte fundamental de registro escrito sobre a história das "pessoas comuns" desses municípios da região, assim como pela possibilidade que esse tipo de fonte nos sinaliza de travar contato direto com esses sujeitos e os recantos de suas memórias. Assim, são realizados registros dos depoimentos orais para que se possa descobrir os lugares da memória, seja no seu sentido concreto (acervos, espaços 
e manifestações), seja no abstrato (as lembranças), nos ajudando a rastrear o passado e suas expressões no presente, de modo a comunicá-lo à geração atual.

Para "provocar" os participantes sobre a memória e a escrita da história local por seus próprios sujeitos, são utilizados materiais (textos, filmes, etc.) que remetam a tal debate e à compreensão sobre a relevância dessa perspectiva da história. Realizada essa reflexão, passamos ao levantamento do que a equipe já sabe e do que deseja saber sobre a história da escola, da comunidade, da cidade e das suas práticas culturais, seguindo-se da identificação e da consulta de outras testemunhas dessa história. Posteriormente, cuidamos dos aspectos operacionais: transcrição dos depoimentos orais; busca nos acervos definidos; registro fotográfico e filmagem das manifestações culturais; organização do material recolhido: digitalização e arquivamento; montagem dos roteiros sobre os lugares de memória identificados e da forma de apresentá-los à comunidade mais ampla das diferentes cidades da região, e especialmente aos jovens estudantes.

\section{CONSIDERAÇÕES}

Como foi discorrido neste texto, o projeto Negras Memórias tem cumprido até o presente seu objetivo de contribuir para a maior visibilidade dos diferentes espaços e instâncias sociais e o que eles podem nos dizer do papel da população negra na história do Brasil e particularmente nesta região do estado do Ceará. Isso tem se expressando tanto nos seminários formativos abertos a toda a comunidade acadêmica e das cidades onde a Unilab está inserida, quanto no contato e catalogação das expressões desse pertencimento étnico-racial e dessa experiência histórica da população afrodescendente no país. A conclusão da primeira edição desta ação de extensão poderá também contribui no fortalecimento desse processo de visibilização e afirmação na medida em que também se estenderão ao espaço escolar, alcançando os estudantes do Ensino Básico. Ao fim, esperamos que o projeto se concretize como uma importante oportunidade para o desenvolvimento de produtos, materiais, espaços e atividades que também expressem essa diversidade étnico-racial na formação social da população dessa região do Ceará, assim como do seu território mais amplo.

\section{REFERÊNCIAS}

BRASIL. Lei n 9.394, de 20 de dezembro de 1996. Lei de Diretrizes e Bases da Educação Nacional, Brasilia, D.F. Disponível em: http://www2.senado.leg.br/bdsf/bitstream/handle/id/70320/65.pdf -2005. Acesso em: 13 set. 2017. 
D'ASSUNÇÃO, J. B. Representações e práticas sociais: rediscutindo o diálogo das duas noções no âmbito da História Cultural Francesa. In: SANTOS, R. M. dos; BORGES, V. R. (Org.). Imaginário e representações: entre fios, meados e alinhavos. Uberlândia: Asppectus, 201 I .

FUNES, Eurípedes Antônio. Negros no Ceará. In: SOUZA, Simone(coord.). Uma Nova História do Ceará, Fortaleza: Demóclito Rocha, 2000.

HALL, Stuart. Da Diáspora: Identidades e mediações culturais. Belo Horizonte: Ed. UFMG, 2003.

MARTINS, Angela Maria Souza. Educação e história cultural: algumas reflexões teóricas. In: LOMBARDI, José Claudinei, CASIMIRO, Ana Palmira Bittencourt Santos e MAGALHÃES, Lívia Diana Rocha (Orgs.).

História, cultura e educação. Campinas, SP: Autores Associados, 2006. pp. 109 - 135.

LE GOFF. Jacques. Memória e História. 4 ed. Campinas, SP: Ed. da Unicamp, 1996.

LE GOFF. Jacques. A História Nova. 4 ed. São Paulo: Martins Fontes, 1988.

MOORE, Carlos. Racismo e Sociedade: novas bases epistemológicas para entender o racismo. Belo Horizonte: Mazza Edições, 2007.

MOREIRA, Antônio Flávio Barbosa e CANDAU, Vera Maria. Educação escolar e cultura(s): construindo caminhos. In: Educação como exercício de diversidade. - Brasília: UNESCO, MEC, ANPED, 2005.

OLIVA, Anderson Ribeiro. A história africana nas escolas brasileiras. Entre o prescrito e o vivido, da legislação educacional aos olhares dos especialistas (1995-2006). HISTÓRIA, São Paulo, 28 (2): 2009.

SILVA, Eduardo. O negro e a conquista da abolição. In: FONSECA, Denise P. R. (org.) Resistência e Inclusão. V.I. Rio de Janeiro: PucRio, 2003.

SILVÉRIO, Valter Roberto. Ações Afirmativas e Diversidade Étnico-Racial. In: Ações Afirmativas e combate ao racismo nas Américas. Sales Augusto Santos (Org.). Brasília: Secretaria de Educação Continuada, Alfabetização e Diversidade, 2005.

SOBRINHO, José Hilário Ferreira. Catirina, minha nêga, tão querendo te vendê: Escravidão, tráfico e negócios no Ceará do século XIX (I850-188 I). Fortaleza: SECULT/CE, 20 I I.

ZAMBONI, Ernesta. O ensino da história e a construção da identidade. SÃO PAULO (Estado) Secretaria da Educação. Coordenadoria de Estudos e Normas Pedagógicas. História. São Paulo: SE/CENP, 1993. Série Argumento. 